\title{
Professional culture forming process by penal system students (pedagogical, psychological and environmental aspects)
}

\author{
Abduljabar Yunusov ${ }^{1}$, Muslim Yunusov ${ }^{1, *}$, and Michael Olenev ${ }^{2}$ \\ ${ }^{1}$ Academy of the Federal penitentiary service of Russian Federation, 1 Sennaya str., Ryazan, 390000 , \\ Russian Federation \\ ${ }^{2}$ Research Institute of the Federal Penitentiary Service of Russia, Narvskaya str., 15 a, building 1, \\ 125130, Moscow, Russian Federation
}

\begin{abstract}
The penitentiary system puts forward special requirements for students and to the level of their professional culture. The specificity of penal system imposes the fulfillment of certain specific tasks on cadets. It determines the main directions of formation of a students' professional culture. The current state and development of penitentiary system of Russian Federation dictates the need for future specialists to master a complex of certain knowledge, skills and abilities that allow them to effectively fulfill office tasks. The peculiarity of conditions of activity of penal system employees is also associated with the fact that they constantly have to deal with persons associated with criminal activity. In the process of penal system employees training, emphasis is placed on the development of professional, spiritual, moral and cultural values. The key condition for achieving law and order in society and institutions of penitentiary system and reducing social tension is the organization of process of forming the professional culture of students in the penitentiary sphere.
\end{abstract}

\section{Introduction}

For more effective training of students in the penal system, it is necessary to pay close attention to what regulates social relations, helps people to better understand each other, gain experience, regulate relationships and a person's worldview - this is about culture.

It is important to understand that the formation of professional and moral qualities of a personality of an employee of penitentiary system occurs throughout his/her life and professional path, but the stage of study at the university is of the greatest importance in this process, since it is during this period that basic moral principles, foundations of professionalism, and self-improvement skills are laid, development of intelligence, circle of interpersonal interactions in the future official activity is determined. The formation of internal readiness for students' professional and moral self-determination begins with them already at the first stages of training in an educational institution.

\footnotetext{
*Corresponding author: lonru787@mail.ru
} 
A special role in organizing training for students of educational institutions of penal system is assigned to pedagogical methods of forming the legal and moral components of professional culture of future specialists in order to carry out legal activities in accordance with moral, pedagogical, and legal prescriptions.

The purpose of the study is to reveal pedagogical foundations in the organization of formation of professional culture of students in the penal system. To achieve this goal, it is necessary to fulfill a number of tasks:

- to analyze the conceptual apparatus of term "professional culture of students of penitentiary sphere";

- to study the process of formation and development of professional culture of students of penitentiary system;

- to identify ways to implement a complex of pedagogical conditions that contribute to the development of a structural and professional psychological model of training employees of penal system using practice-oriented training.

\section{Methods}

Pedagogical approaches in organizing the formation of professional culture of students has been the subject of research by various authors. Thus, L. V. Elagina defines an important condition for the presence of a competence-based approach when organizing the formation of a culture of professional activity of a future specialist. Danilova M.M. points to the need for a humanitarian approach as a principle of organizing the development of professional culture of specialists in the course of educational process at a university. Svetlichny E.G. emphasizes contextual training as a basis for the formation of professional culture of future lawyers. Pedagogical science also contains other studies of different years on the stated issues, but, despite this, the issue of pedagogical approaches in organizing the formation of professional culture of students in the penal system remains quite relevant, since this issue is most acutely manifested in professions that are characterized by increased stressfulness. and even extremeness associated with the risk of life. One of these specialties is the future practical activity of a student of penal system.

To understand the term "professional culture", one should first define the concept of "culture". In various author's interpretations "culture" denotes a historically determined level of development of society, creative forces and abilities of a person, expressed in the types and forms of organization of life and activities of people, as well as the material and spiritual values they create. A part of the general culture of an individual is professional culture, which is a set of worldview attitudes and special knowledge, value orientations of an individual, which are manifested in labor activity and ensure its higher efficiency.

The concept of "professional culture" is close in meaning to the concepts of "professionalism" and "competence". All these concepts characterize the personality of a specialist, the effectiveness of his/her activities, but they have significant differences.

Professionalism means the professional suitability of a specialist, which should be understood as a set of psychological and psychophysiological characteristics of a person, necessary and sufficient to achieve socially acceptable labor efficiency in a certain activity. Professional competence is defined as a graduate's possession of an appropriate system of competencies, including personal attitude to the subject of activity; the ability to practice on the basis of knowledge, skills, and abilities acquired.

The research methodology is built on the basis of an analysis of theoretical provisions and pedagogical practice of organizing the formation of professional culture of students in the penal system. In order to obtain reliable and scientifically grounded results, comparative legal, linguistic, statistical and specific sociological research methods were comprehensively applied. 
The results of the study were supported by the methodology "Diagnostics of professional value orientations of an individual". Comparative analysis of structural and dynamic characteristics of professional value orientations of students was carried out using the pseudo-longitudinal method. To process the obtained quantitative results, following methods of mathematical statistics were used: Kruskal-Wallis H-criterion, Mann-Whitney U-criterion, values of average value (M) and partial (percentage) analysis.

\section{Results}

The study shows that the organization of process of forming the professional culture of students in penitentiary universities is significantly influenced by such psychological functions as memory, thinking, attention, abilities, interests, inclinations, motivation and value orientations. It is also necessary to take into account the fact that natural characteristics of a student's personality are far from the last place in the formation of his/her professional and moral qualities. In this regard, we believe that it is advisable to consider professional culture of a student of penitentiary system based on the student's ability to acquire the necessary competencies in the process of training in a penitentiary institution and adapt to the requirements of professional activities of personnel of penitentiary bodies and institutions of modern Russia.

As a result of the study, it was determined that professional culture of students in the penal system can be understood as a systematic approach to the education of a student as a person, with a certain set of knowledge, skills, experience and values in the field of criminal executive activity, aimed at fulfilling official tasks and ensuring human rights, protection of health of convicts, involvement of convicts in labor, as well as provision of their general and vocational education and vocational training in accordance with the principles of humanism, legality and justice.

In the process of training highly qualified specialists, based on the results of the study, it is advisable to prepare and develop with the subsequent introduction of a complex of pedagogical conditions for training together with a structural and functional model for formation of professional culture in educational institutions of penal system in the preparation of specialists.

When analyzing the data obtained from all groups (experimental and control groups) using the developed methodology, it can be noted that development of professional culture was much higher in the experimental groups, which indicates the success of the study and shows the growth of professional culture of future specialists of penal system.

In the course of the study, the content characteristics of students professional value orientations were also identified. At the final stage of training, students' opinion about the importance of goal-setting in professional activity changes. The goal becomes more conscious and is perceived as a result and a condition for success in fulfilling the assigned professional tasks related to ensuring the isolation of convicts.

\section{Discussion}

The formation of professional culture of an employee of penitentiary system occurs throughout his/her entire life and professional path, but the stage of study at the university is of greatest importance in this process, since basic moral principles, foundations of professionalism, skills for self-improvement, development of intelligence are laid during this period.

Meanwhile, age-related patterns of formation of a person's professional culture were the subject of scientific research by both foreign and domestic scientists. Thus, I. Kant in his 
works singled out following four stages of professional and moral self-determination in accordance with the age-related periodizations of development adopted in pedagogy: stage of children's play; stage of adolescent fantasy; stage of preliminary choice of profession and stage of practical decision-making. A. Sh. Buhler, who is considered the founder of scientific theory of stages of professional and moral life, developed the concept of five phases of life cycle. With regard to our issue, the most attention is paid to the second phase, highlighted by it - the age period from 16-20 to 25-30 years, characterized by the search for personality recognition. It is at this stage of development that a person optimally determines the area of activity that best suits his/her abilities and aspirations, clarifies life vocation, accumulates a certain experience of life success and service achievements.

At the same time, the main resources necessary for development of professional culture and socialization of students, according to Sergeeva M.G. are the level of development of professional competencies of a young specialist, the level of professional education, the system of continuous professional education, and also, according to R.M. Gillies, an organized social and professional environment. The researchers emphasize that the optimal type of adaptive behavior should be formed not as a blind obedience to external requirements, but as a choice of optimal behavioral solution that presupposes continuous professional self-development. The end result of professional socialization make components of professional competence: professional and personal competence.

Many scholars agree that one of the leading professional indicators of readiness to work with convicts consist of value orientations embedded in the professional culture of employees, who, on the one hand, act as a regulator of professional behavior of young specialists in penitentiary institutions, and on the other hand, act as meaningful result of professional activity of a particular subject of labor.

The study on the organization of formation of professional culture of students of penal system was carried out in 2018-2019. on the basis of educational institutions of penitentiary system, which was attended by 230 people.

In the course of work, the students were divided into groups: who participated in the experiment itself (there were three groups) and two control groups. The variable type of experiment was chosen as the basis. To determine professional culture of students of penal system in the experimental groups, different conditions for provision of pedagogical services were created. The students of two control groups continued their training according to the standard program.

According to a complex of various pedagogical methods, the main goal of the study was realized - the formation of professional culture of students of penal system, conditions were determined and a model was developed for formation of their professional culture.

The process of organizing the formation of professional culture of employees of penal system with the help of implemented structural and functional model consisting of a cognitive, motivational and practical stage was carried out better in the experimental groups than in the control groups.

During the research, the content characteristics of professional-value orientations of students were also highlighted (tables 1 and 2). The comparison was carried out with students to demonstrate the clarity of pedagogical features of formation of professional culture of students ( 90 cadets and 90 students).

Comparative analysis of content of professional values of cadets and students demonstrates that the importance of relationships is more pronounced among cadets in the first year $(M=9.39)$ than among students $(M=7.42)(p=0.021)$. The result shows satisfaction with interpersonal and intergroup interaction with colleagues, course officers and university teachers. The conflict-free nature of cadets' relations is consistent with the general tendency to overcome professional communication and organizational barriers both in the learning process and in the course of performing official tasks. 
Table 1. The results of a comparative analysis of professional value orientations of cadets and 1st year students (U-criterion Mann-Whichi).

\begin{tabular}{|c|c|c|c|c|}
\hline \multirow{2}{*}{ Method scales } & \multirow{U}{*}{$\mathbf{U}$} & \multirow{2}{*}{$\mathbf{P}$} & \multicolumn{2}{|c|}{ Average value } \\
\cline { 4 - 5 } & & & cadets & students \\
\hline Values - attitudes & 312.42 & $0.021^{*}$ & 9.39 & 7.42 \\
\hline Values - knowledge & 211.73 & $0.014^{*}$ & 9.67 & 7.00 \\
\hline Values - goals & 414.09 & $0.03^{*}$ & 9.11 & 6.93 \\
\hline Values - result & 214 & 0.708 & 9.48 & 9.43 \\
\hline Values - qualities & 170.06 & 0.214 & 8.11 & 8.06 \\
\hline Values - skills & 512.24 & 0327 & 8.22 & 8.41 \\
\hline
\end{tabular}

* statistically significant differences are italicized.

The first year of study is quite difficult for cadets. During this period, the process of adaptation to the conditions of training and service is actively underway. The specificity of vocational training in departmental universities of penitentiary system lies in the educational process, compliance with statutory relations, ensuring security and order, implementation of access control, performing the functions of a guard service, serving in squads, etc.

Higher indicators of cadets' value-knowledge scale $(M=9.67)$ show the importance of the process of special education for achieving professional and personal self-development $(\mathrm{p}=0.014)$.

Table 2. The results of a comparative analysis of professional-value orientations of cadets and 5-year students (U-criterion of Mann-Whichi).

\begin{tabular}{|c|c|c|c|c|}
\hline \multirow{2}{*}{ Method scales } & \multirow{2}{*}{$\mathbf{U}$} & \multirow{2}{*}{$\mathbf{P}$} & \multicolumn{2}{|c|}{ Average value } \\
\cline { 4 - 5 } & & & cadets & students \\
\hline Values - attitudes & 510.09 & 0.106 & 9.3 & 9.12 \\
\hline Values - knowledge & 512.51 & $0.003^{*}$ & 8.51 & 6.05 \\
\hline Values - goals & 413.18 & $0.009^{*}$ & 8.15 & 7.3 \\
\hline Values - result & 312.7 & 0.325 & 9.26 & 9.03 \\
\hline Values - qualities & 410.9 & $0.011^{*}$ & 9.07 & 8.6 \\
\hline Values - skills & 212.08 & $0.048^{*}$ & 8.09 & 6.91 \\
\hline
\end{tabular}

Interesting results were obtained when comparing groups on the value-knowledge scale in the 5th year. For cadets, this indicator turned out to be significantly higher $(\mathrm{M}=8.51)$ than for students $(M=6.05)$. The obtained result indicates that the professional activity of employees of correctional institutions requires from their employees development and deepening of a system of special knowledge aimed at their professional implementation.

For cadets, the value of achieving the goal in the course of fulfilling assigned service tasks is still important $(\mathrm{p}=0.009)$. At the same time, the awareness and achievement of professional goals by future employees significantly affects the independence of decisionmaking, on which the lives of other people may depend. Despite the fact that the level of significance of target component in the activity of cadets by the 5th year of study decreases, it remains in the range of high indicators.

When analyzing the results of formation of young specialists in the penitentiary sphere in the course of training (table 1 and 2), it can be noted that the target component of professional activity determines the development of cadets' professional skills, which, according to I. I. Kuptsov and G. S. Karpova, "are located in the cognitive-prognostic (cognitive), communicative, organizational-managerial and educational directions". 
For a group of cadets at the final stage of training, personal meaning acquires a special role, which consists in the need for further development of those professionally important qualities that affect the productivity of official activity and the setting of tasks for personal self-development within the chosen field of activity. Future employees develop a reflexive attitude towards the development of such personally significant qualities as self-education, responsibility, discipline, independence, and exactingness. The empirical research conducted by Ya. N. Polyakova makes it possible to expand the list of significant professional characteristics of specialists in the penitentiary sphere, adding to them the following: "good knowledge and fulfillment of their personal duties, respect for the rights of other employees, desire to bring the work started to the end, compliance with official ethics".

Based on the results obtained, the students of the departmental higher educational institution have an identical idea of the role of professional qualities in the performance of official activities. The absence of a pronounced dynamics of cadets' ideas about the importance of professional qualities indicates an understanding of obligation to develop and improve these characteristics through the acquisition of practice-oriented knowledge, specialized skills and professionally important personality traits of a professional in the penitentiary sphere.

It should be noted that professional culture of students of penitentiary system at the present stage is formed within the framework of a practice-oriented approach.

Modern higher education has developed a number of approaches to practice-oriented learning. The first of them is associated with the peculiarities of organization of educational, industrial and pre-diploma practice of students by immersing in a professional environment, correlating ideas about profession with the requirements of society, realizing own role in the profession (Yu. Vetrov, N. Klushina). The second approach is associated with the introduction of professionally oriented learning technologies that contribute to the formation of personality traits that are significant for future professional activity in students, as well as knowledge, skills and abilities that ensure the performance of functional duties in the chosen specialty at the required level (P. Obraztsov, T. Dmitrienko, R. Romashov). The third approach is associated with the use of possibilities of contextual (professionally directed) study of core and non-core disciplines in practice-oriented education (A. Verbitsky, E. Plotnikova, V. Shershneva).

We believe that practice-oriented teaching approach used in penitentiary universities has significant educational opportunities and provides a developing educational result, expressed in the formation of a stable cognitive interest, an increase in the level of both knowledge and skills, as well as professional culture of future employee.

\section{Conclusion}

A modern specialist in the penitentiary sphere should not only have deep legal knowledge, but also be professionally competent, mobile, able to adapt to emerging changes in society, be distinguished by civic maturity, patriotism, and be capable of ensuring the activities of penal system at a qualitatively new level. In accordance with this, it is required to constantly improve personal and professional qualities of employees, increase their educational qualifications. The high level of training and professional culture of the staff of penitentiary system largely depends on the quality of their professional training at the departmental university.

Fundamental in the concept of "professional culture" is the presence by an employee not only certain professional qualities (a high level of special and psychological training, ability to effectively solve non-standard tasks of official activity, etc.), but also moral qualities. These qualities include responsibility, perseverance, dedication, initiative. The professional 
culture includes such elements of general culture of individuals as literacy, spirituality, ethics, and tolerance.

Thus, the professional culture of an employee of penitentiary system is a systemic quality that reflects professional skill, a complex of moral convictions, which manifests in the process of service.

The following main tasks of professional culture forming by students of penitentiary sphere can be distinguished:

- mastering professional knowledge, skills, allowing to perform official duties at a high level;

- development of intellectual, moral, volitional qualities of individuals;

- development of a desire for self-improvement.

The study on the organization of formation of professional culture of students in the penitentiary system showed that the development of professional culture was much higher in the experimental groups, which indicates the success of study and shows the growth of professional culture of future specialists of penitentiary system.

All of this affects the formation of professional culture of student of penitentiary sphere. In connection with the above distinctive features of organization of educational process, already in the first year of study, the value of relations in the professional activity of a future employee of penitentiary sphere is actualized. By the end of the training, goal-setting becomes an important element of professional culture of an employee of penitentiary system. The goal becomes more conscious and is perceived as a result and condition of success in fulfilling the assigned professional tasks.

The use of a practice-oriented approach in pedagogical work when training employees in departmental educational organizations can significantly increase the effectiveness of educational process. This is facilitated by the system of selection of content of university educational material, which helps cadets to assess the significance, practical relevance of acquired knowledge and skills. In the practice-oriented educational process, the cadets' life experience is not only actualized, but a new one is also formed on the basis of acquired legal knowledge. It becomes the basis for both general development of cadets and formation of their professional culture.

Thus, when analyzing the theoretical and practical material, it can be noted that in educational institutions, in the preparation and formation of professional culture of employees of penal system, there are certain features. For pedagogical correction of this situation, it is necessary to decide on the choice of a set of tools and methods, as well as a set of theoretical and methodological approaches that would ensure the formation of sufficient professional competencies in particular, and for the formation of professional culture in general.

\section{References}

1. A.A. Votinov, Problems of modern pedagogical education 53-6, 98-106 (2016)

2. D.A. Erokhin, Bulletin of the Stavropol State University 60, 167-174 (2009)

3. I.I. Ilidzhiev, Applied legal psychology 2, 209-214 (2015)

4. N.A. Samoilik, Modern research of social problems 7, 141-166 (2016)

5. I. Kant, Foundations of metaphysics of morality (1965)

6. M.G. Sergeeva, I.A. Pugachev, J.M. Kalinina, S.L. Sapfirov, N.V. Ippolitova, S.U. Parfenov, A.V. Paklina, Espacios 39(38), 27 (2018)

7. R.M. Gillies, Cooperative leaning. Integrating theory and practice (Sage Publications, INC., 2007) 
8. Z. Velkovski, E.L. Rizova, International Journal of Cognitive Research in Science, Engineering and Education 3(1), 81-88 (2015)

9. N.N. Belogortsev, Symbol of Science 8-2, 112-114 (2016)

10. N.A. Samoilik, Bulletin of the Kemerovo State University 21(3), 741-750 (2019)

11. I.I. Kuptsov, G.S. Karpova, Applied legal psychology 4, 20-30 (2013)

12. Ya.N. Polyakova, Humanities, socio-economic and social sciences 4, 275-278 (2014)

13. R.A. Romashov, Bulletin of the Samara Institute of Law 2(4), 67-70 (2011) 